\title{
Analysis of Access to Public Support for Agriculture Modernisation from Rural Development Programme
}

\author{
Sabahudin Bajramovic ${ }^{1}$, Dejan Jankovic ${ }^{2}$, Sladjan Stankovic ${ }^{3}$, Sebastian Moisa ${ }^{4}$, \\ Cosmin Salasan $^{*}$ \\ ${ }^{1}$ University of Sarajevo, Faculty of Agriculture, Bosnia and Herzegovina \\ 2 University of Novi Sad, Faculty of Agriculture, Serbia \\ ${ }^{3}$ Institute for Science Application in Agriculture, Belgrade, Serbia \\ ${ }^{4}$ Banat's University of Agricultural Sciences and Veterinary Medicine "King Michael Ist of Romania" from \\ Timisoara, Romania
}

\begin{abstract}
The most popular measure of the National Rural Development Programme in Romania for 2007-2013 was the measure 121 addressing the support for modernisation of agriculture While the success at the level of the Programme is measured by the achievement level of the assumed indicators the present analysis is focused on differences between the volumes of proposed, selected, contracted and concluded projects. These differences as observations and findings contribute as learning points to the further use of public support for investments in agriculture by three main categories of users: the administration with the procedural enhancement in programme implementation, the beneficiaries improving their approach and readiness for applications/projects and the consultants in perfecting their tools and work to support and smoothen the resources transfer in the process.
\end{abstract}

Key words: RDP, public support, agriculture modernization.

\section{Introduction}

The overall rationale and the general objective of the Measure 121 of the National Rural Development Programme 2007-2013 [1] was addressing the increase of general competitiveness of the farming sector by an enhanced level of performance of both human and production factors. Operationally this general target translates into direct investments in farms non-discriminatory regarding their production profile and considering the situation of the dual Romanian agriculture with a large semisubsistence sector, a highly fragmented agricultural land property, the low level of

\section{* Corresponding author: Cosmin Salasan, cosminsalasan@usab-tm.ro}

(cc) BY-NC-ND ${ }^{\odot} 2017$ Sabahudin Bajramovic et al., published by De Gruyter This work was licensed under the Creative Commons Attribution-NonCommercialNoDerivs 3.0 License association, the reduced number of commercial operations in agriculture and the relative large distance to the community standards an image that fits a wider geographical area in Central, Eastern and South-Eastern Europe [3] and [4].

A general consideration about the implementation success of this measure ranks it in the first position among all measures of the Axis 1 of the programme with almost $70 \%$ of the projects under this measure $(69.70 \%)$ dealing with investments for field crops, mainly in purchasing equipment and machinery, representing 1976 projects from the total of 2835 approved. The mounting of private contribution was highly relevant as the public value of projects amounted de 382052.77 thousand EUR from the total of 878877.43 thousand EUR. The remaining 30\% covers investments in permanent crops, horticulture, viticulture different animal productions and mixed investments. Compared to the target indicator value the number of farms benefiting from this 
type of support, little under 3000 units (2 835) is far below 10\% (7.59\%), however the achievements in terms of contracted amounts and total value of the investments exceeds the projected levels by almost $1 / 4(122.65 \%)$ reaching 1.8 billion EUR (1 878101.38 thousand EUR). Also, the financial execution rate expressed in performed payments goes above 85\% (87.74\%) level considered highly successful from two perspectives: the capacity of co-financing the investments from the side of the beneficiaries of over 1 billion EUR and from a comparative perspective with the other interventions and measures of the programme within the same axis. [b]

The implementation progress has a naturally heterogeneous evolution at different stages along the different calls for projects from 2008 the first year of the programme approved by the Commission in February 2008 until 2014 as part of the $\mathrm{N}^{+2}$ contracting rule for the still available financially committed resources.

\section{Material and Methods}

The secondary research relates exclusively on the official data provided by the specific monitoring and reporting instruments of the programme as well as the reference base represented by the programme indicators and specifications. The observations and the findings used to conclude are strictly quantitative with no qualitative assessments. Punctually the observations are articulated based on deductive assessments to generate the learning points as research question for the present paper.

\section{Results and Discussions}

The research results are organised by the sequence of results following the descriptive level of the total submitted projects by each organised session, the total number of selected projects corresponding to each session and the respective final number of contracted projects. In order to check any important variations in evolution of projects' number or volume, the value of the public contribution is also screened for the same iterations. Further interest is manifested in determining a number of rations between the selected and the submitted projects, the contracted and the selected projects, and the contracted and the submitted projects as share from the totals, and respectively the value differences for the same ratios. Also the purely statistical average value of the Submitted, Selected and Contracted projects is determined in order to observe any potential trends in distribution disregarding the type of productions and the requested public contribution variations by beneficiary. The evolution of the number of projects submitted, selected and contracted over the entire programme period is presented in Table 1.

With the aim of illustrating and increasing the visibility of any findings the data is further represented graphically in Figure 1 allowing an easier observation of variations in volumes.

Table 1

Number of projects submitted/selected/contracted for Measure 121, 2008-2014, (no.)

\begin{tabular}{|cccc|}
\hline Session & Submitted & Selected & Contracted \\
\hline $\mathbf{2 0 0 8}$ & 712 & 306 & 283 \\
\hline $\mathbf{2 0 0 8}$ & 728 & 279 & 246 \\
\hline $\mathbf{2 0 0 8}$ & 627 & 222 & 181 \\
\hline $\mathbf{2 0 0 8}$ & 1,514 & 503 & 399 \\
\hline $\mathbf{2 0 0 9}$ & 948 & 281 & 196 \\
\hline $\mathbf{2 0 1 0}$ & 691 & 254 & 119 \\
\hline $\mathbf{2 0 1 0}$ & 325 & 188 & 127 \\
\hline $\mathbf{2 0 1 1}$ & 571 & 300 & 191 \\
\hline $\mathbf{2 0 1 2}$ & 1,108 & 457 & 292 \\
\hline $\mathbf{2 0 1 2}$ & 627 & 378 & 242 \\
\hline $\mathbf{2 0 1 3}$ & 303 & 210 & 159 \\
\hline $\mathbf{2 0 1 4}$ & 584 & 471 & 400 \\
\hline Total & 8,738 & 3,849 & 2,835 \\
\hline Source: Calculations based on the & Annual Progress & Report NRDP \\
\hline 2007-2013, 2015 [2] & & & \\
\hline
\end{tabular}

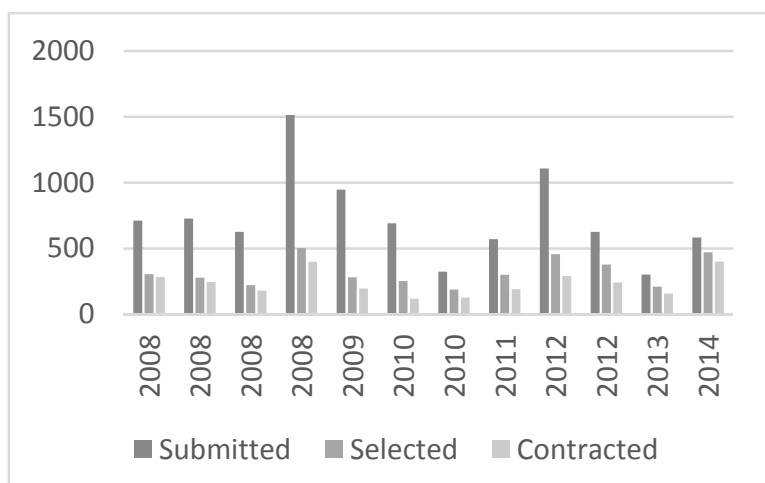

Source: Calculations based on the Annual Progress Report NRDP 2007-2013, 2015 [2]

Fig. 1. Number of projects

submitted/selected/contracted for Measure 121, 2008-2014, by session (no.)

A first observation relates to the change in differences between the total number of submitting projects and the subsequent number of selected projects. This finding observed over the second half of the programming period can indicate an increase in the maturity of the projects. The large gaps in the last session of 2008 and the first session of 2012 are apparent considering the total number of submitted projects exceeding 
1000 respectively 1500 projects. The differences between the selected and contracted projects have a naturally distributed difference, basically influenced by the contracting financial amounts allocated to each call.

Although with no direct or correlated links the total demanded public contribution in EUR by the total number of projects, potentially biased by the type of investments or type and size of productions, is presented in Table 2 and graphically illustrated in Figure 2 proving that the general trend induced by physical number is closely followed by the total value for this measure's projects.

Table 2

Value of projects submitted/selected/contracted for Measure 121, 2008-2014, by session (thou. EUR)

\begin{tabular}{|cccc|}
\hline Session & Submitted & Selected & Contracted \\
\hline $\mathbf{2 0 0 8}$ & $152,201.31$ & $61,545.22$ & $53,549.24$ \\
\hline $\mathbf{2 0 0 8}$ & $143,093.03$ & $62,279.28$ & $52,408.19$ \\
\hline $\mathbf{2 0 0 8}$ & $138,023.95$ & $58,781.79$ & $44,596.54$ \\
\hline $\mathbf{2 0 0 8}$ & $551,496.09$ & $212,054.49$ & $140,562.47$ \\
\hline $\mathbf{2 0 0 9}$ & $539,621.18$ & $175,381.95$ & $104,663.34$ \\
\hline $\mathbf{2 0 1 0}$ & $424,869.81$ & $155,433.74$ & $59,387.15$ \\
\hline $\mathbf{2 0 1 0}$ & $171,745.58$ & $100,553.80$ & $58,814.76$ \\
\hline $\mathbf{2 0 1 1}$ & $241,701.22$ & $140,703.16$ & $65,611.83$ \\
\hline $\mathbf{2 0 1 2}$ & $422,081.30$ & $162,722.74$ & $75,447.97$ \\
\hline $\mathbf{2 0 1 2}$ & $210,221.24$ & $113,407.13$ & $47,804.62$ \\
\hline $\mathbf{2 0 1 3}$ & $13,134.38$ & $9,266.78$ & $7,129.08$ \\
\hline $\mathbf{2 0 1 4}$ & $107,491.52$ & $81,999.24$ & $65,906.08$ \\
\hline Total & $3,115,680.61$ & $1,334,129.32$ & $775,881.26$ \\
\hline
\end{tabular}

Source: Calculations based on the Annual Progress Report NRDP 2007-2013, 2015 [2]

\section{$600.000,00$ \\ $500.000,00$ \\ $400.000,00$ \\ $300.000,00$ \\ $200.000,00$ \\ $100.000,00$ \\ 0,00

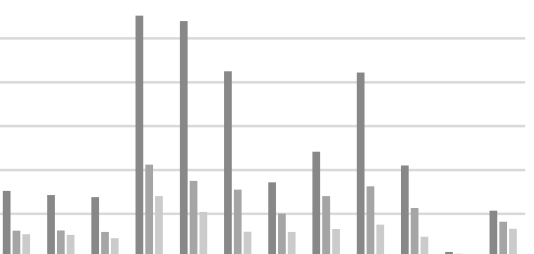 \\ 号 \\ Submitted $\square$ Selected Contracted \\ Source: Calculations based on the Annual Progress Report NRDP 2007-2013, 2015 [2] \\ Fig. 2. Value of projects \\ submitted/selected/contracted for Measure 121, 2008-2014, by session (thou. EUR)}

This observation can be interpreted by the fact that possibly, most beneficiaries were targeting the maximum possible amount for the projects maintaining an almost proportional distance when addressing the public contribution amounts.
The use of graphic expression enables for the first time the finding related to the session of 2013 also valid for other aspects of the research further in this paper which leads to the conclusion that this year could be excluded from the general research as being highly atypical due to its extremely reduced figures.

Of a considerably higher interest for the observation of behaviour and potentially change in quality of the applications are the shares between the selected and the submitted projects, of the contracted projects out of the selected ones and finally the ratios of contracted projects from the total number of submitted project applications introduced by calculated shares in Table 3 and graphically presented in Figure 3.

Table 3

Reported shares by stages from submission to contracting for Measure 121, 2008-2014, by session (\%)

\begin{tabular}{|cccc|}
\hline Session & $\begin{array}{c}\text { Selected/S } \\
\text { ubmitted }\end{array}$ & $\begin{array}{c}\text { Contracted/ } \\
\text { Selected }\end{array}$ & $\begin{array}{c}\text { Contracted/ } \\
\text { Submitted }\end{array}$ \\
\hline $\mathbf{2 0 0 8}$ & $43 \%$ & $92 \%$ & $40 \%$ \\
\hline $\mathbf{2 0 0 8}$ & $38 \%$ & $88 \%$ & $34 \%$ \\
\hline $\mathbf{2 0 0 8}$ & $35 \%$ & $82 \%$ & $29 \%$ \\
\hline $\mathbf{2 0 0 8}$ & $33 \%$ & $79 \%$ & $26 \%$ \\
\hline $\mathbf{2 0 0 9}$ & $30 \%$ & $70 \%$ & $21 \%$ \\
\hline $\mathbf{2 0 1 0}$ & $37 \%$ & $47 \%$ & $17 \%$ \\
\hline $\mathbf{2 0 1 0}$ & $58 \%$ & $68 \%$ & $39 \%$ \\
\hline $\mathbf{2 0 1 1}$ & $53 \%$ & $64 \%$ & $33 \%$ \\
\hline $\mathbf{2 0 1 2}$ & $41 \%$ & $64 \%$ & $26 \%$ \\
\hline $\mathbf{2 0 1 2}$ & $60 \%$ & $64 \%$ & $39 \%$ \\
\hline $\mathbf{2 0 1 3}$ & $69 \%$ & $76 \%$ & $52 \%$ \\
\hline $\mathbf{2 0 1 4}$ & $81 \%$ & $85 \%$ & $68 \%$ \\
\hline Total & $44 \%$ & $74 \%$ & $32 \%$ \\
\hline
\end{tabular}

Source: Calculations based on the Annual Progress Report NRDP 2007-2013, 2015 [2]

The first positive achievement is indicated by an almost linear progression of the selected/submitted ration that can be read as a positive adjustment to criteria and requirements. The end of the series records shares doubled from the first part of the period for this share. The contracted/selected ration is a mirrored Gaussian evolution where several variables are missing from the reading such as the refuse of the beneficiary to assume the contract after the selection process reason for which we remain at the observation with no interpretation. The most important finding invisible or even mirrored by the initial plain and unprocessed data relates to the widening gap between the contracted and the total submitted number of projects when compared to the ratios of selected projects for the 
total submitted. The positive side of this finding can indicate the existence of a consistent reserve of quality projects representing a good base and favourable grounds for the current and future programmes in terms of well formulate demand.

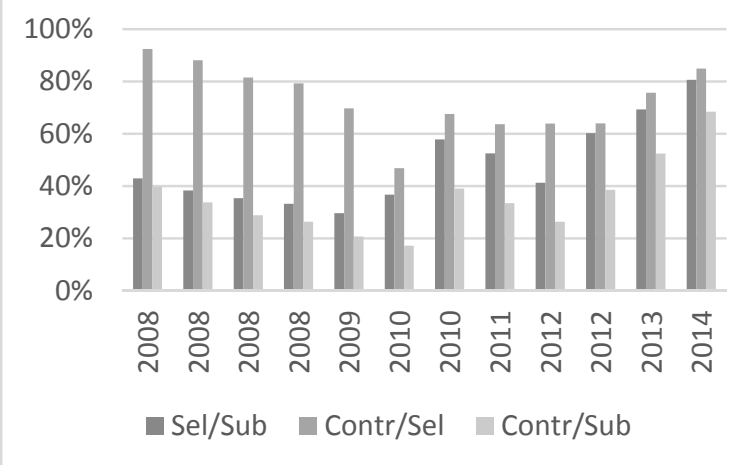

Source: Calculations based on the Annual Progress Report NRDP 2007-2013, 2015 [2]

Fig. 3. Reported shares by stages from submission to contracting for Measure 121, 2008-2014, by session (\%)

The paralleled illustration of shares and values as public contribution proves highly different in the case of differences and ratios between the different stages. If the trend was proportionally following the simple screening of number and values (Tables 1 and 2) in the case of ratios and differences no link or trend can be established (Tables 3 and 4). The residual amounts remaining unselected or uncontracted follow practically no distinct pattern. The lack of a trend does not indicate an error in methodology or in programming approach but underlines the fact that linking the number and the value of the projects does not necessarily highlight positive or negative states. The previously observed widening gap between the selected and contracted projects changes when determined by difference with the submitted ones and is reversed in the case of differences. The amounts demanded by unselected and uncontracted projects as reported difference from the total submitted present relative small differences at the beginning of the period (Table 4). Considering the national scale of the competition these differences can be considered irrelevant as the high rate of contracting from the selected projects expressed in uncontracted amounts due to the limitations of allocated budgets for the different calls are even ten times smaller. For the second half of the period this situation reverses completely reaching and exceeding even the double of amounts remained uncontracted when compared to the projects' value being selected and still uncontracted. The observations refer to the entire analysed period after 2010 and apply even to the disregarded atypical year 2013.
The above observations become highly visible in graphical expression (Figure 4) and support the calculations and differences as from absolute to relative assessment. This change supports entirely the earlier introduced supposition of quality increase of the submitted applications possibly combined with the participation of reserved potential beneficiaries expecting to see the entire implementation process in development.

Table 4

Value differences by stages from submission to contracting for Measure 121, 2008-2014, by session (thou. EUR)

\begin{tabular}{|cccc|}
\hline Session & $\begin{array}{c}\text { Selected/ } \\
\text { Submitted }\end{array}$ & $\begin{array}{c}\text { Contracted/ } \\
\text { Selected }\end{array}$ & $\begin{array}{c}\text { Contracted/ } \\
\text { Submitted }\end{array}$ \\
\hline $\mathbf{2 0 0 8}$ & $90,656.09$ & $7,995.98$ & $98,652.07$ \\
\hline $\mathbf{2 0 0 8}$ & $80,813.75$ & $9,871.09$ & $90,684.84$ \\
\hline $\mathbf{2 0 0 8}$ & $79,242.16$ & $14,185.25$ & $93,427.41$ \\
\hline $\mathbf{2 0 0 8}$ & $339,441.60$ & $71,492.02$ & $410,933.62$ \\
\hline $\mathbf{2 0 0 9}$ & $364,239.23$ & $70,718.61$ & $434,957.84$ \\
\hline $\mathbf{2 0 1 0}$ & $269,436.07$ & $96,046.59$ & $365,482.66$ \\
\hline $\mathbf{2 0 1 0}$ & $71,191.78$ & $41,739.04$ & $112,930.82$ \\
\hline $\mathbf{2 0 1 1}$ & $100,998.06$ & $75,091.33$ & $176,089.39$ \\
\hline $\mathbf{2 0 1 2}$ & $259,358.56$ & $87,274.77$ & $346,633.33$ \\
\hline $\mathbf{2 0 1 2}$ & $96,814.11$ & $65,602.51$ & $162,416.62$ \\
\hline $\mathbf{2 0 1 3}$ & $3,867.60$ & $2,137.70$ & $6,005.30$ \\
\hline $\mathbf{2 0 1 4}$ & $25,492.28$ & $16,093.16$ & $41,585.44$ \\
\hline Total & $1,781,551.29$ & $558,248.06$ & $2,339,799.35$ \\
\hline
\end{tabular}

Source: Calculations based on the Annual Progress Report NRDP 2007-2013, 2015 [2]

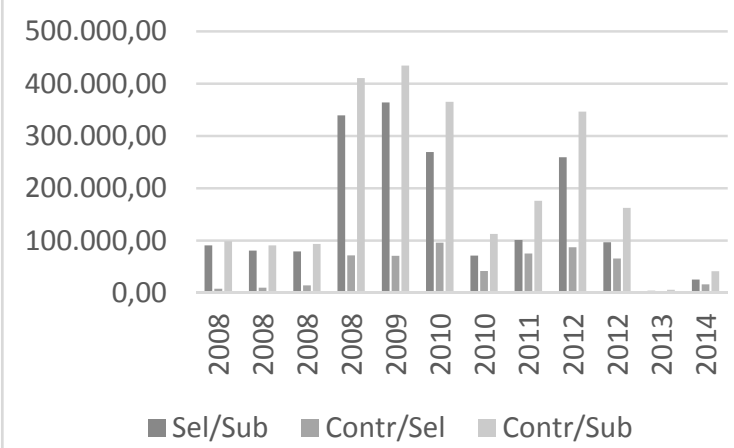

Source: Calculations based on the Annual Progress Report NRDP 2007-2013, 2015 [2]

Fig. 4. Value differences by stages from submission to contracting for Measure 121, 2008-2014, by session (thou. EUR)

A purely statistical view is offered by the calculations of the average value of the submitted, selected and contracted projects (Table 5).

Although with less relevance for the realism of each project application in terms of value and 
intervention nature it provides valuable observations in terms of differences between the average (public) value of the submitted and selected projects and further with the contracted applications.

Table 5

Average value per submitted/selected/contracted for Measure 121, 2008-2014, by session (thou. EUR)

\begin{tabular}{|cccc|}
\hline Session & Submitted & Selected & Contracted \\
\hline $\mathbf{2 0 0 8}$ & $213,765.88$ & $201,128.17$ & $189,219.93$ \\
\hline $\mathbf{2 0 0 8}$ & $196,56.36$ & $223,223.23$ & $213,041.42$ \\
\hline $\mathbf{2 0 0 8}$ & $220,133.89$ & $264,782.84$ & $246,389.72$ \\
\hline $\mathbf{2 0 0 8}$ & $364,264.26$ & $421,579.50$ & $352,286.89$ \\
\hline $\mathbf{2 0 0 9}$ & $569,220.65$ & $624,135.05$ & $533,996.63$ \\
\hline $\mathbf{2 0 1 0}$ & 614862.24 & $611,943.86$ & $499,051.68$ \\
\hline $\mathbf{2 0 1 0}$ & $528,447.94$ & $534,860.64$ & $463,108.35$ \\
\hline $\mathbf{2 0 1 1}$ & $423,294.61$ & $469,010.53$ & $343,517.43$ \\
\hline $\mathbf{2 0 1 2}$ & $380,939.80$ & $356,067.26$ & $258,383.46$ \\
\hline $\mathbf{2 0 1 2}$ & $335,281.08$ & $300,018.86$ & $197,539.75$ \\
\hline $\mathbf{2 0 1 3}$ & $43,347.79$ & $44,127.52$ & $44,836.98$ \\
\hline $\mathbf{2 0 1 4}$ & $184,060.82$ & $174,096.05$ & $164,765.20$ \\
\hline Total & $356,566.79$ & $346,617.13$ & $273,679.46$ \\
\hline
\end{tabular}

Source: Calculations based on the Annual Progress Report NRDP 2007-2013, 2015 [2]

The graphical presentation of data from Table 5 present a Gaussian distribution for the entire period except for 2013 atypical for all the reasons introduced earlier.

\section{$800.000,00$ \\ $600.000,00$ \\ $400.000,00$ \\ $200.000,00$ \\ 0,00

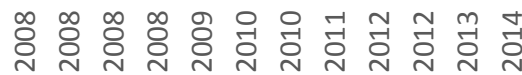 \\ - Submitted Selected Contracted}

Source: Calculations based on the Annual Progress Report NRDP 2007-2013, 2015 [2]

Fig. 5. Average value per

submitted/selected/contracted for Measure 121, 2008-2014, by session (thou. EUR)

However, this distribution does not highlight a higher interest manifested in the middle of the analysed period as facts underline that the largest number of submitted applications was during the last session of 2008 while the largest figures for contracted projects indicate the same 2008 and the 2014 sessions (Figure 5).

A higher average value for all categories of projects in all stages for the middle section of the analysed period (2009-2010) could simply indicate potential beneficiaries with a larger capacity to support the private co-financing contribution resulting in higher total demanded values for the projects under the specific maximum ceiling set by the specifications of the measure.

These observations could also be articulated with the end of the financial crisis and availability of private funding to support the public investments. Eliminating the first and last year for any potential distorted data due to the start and the end of the programme the recovered amounts have multiplied twelve times between 2009 and 2015 [2]. The exponential display of this evolution introduces a partially cumulated series of amounts as reported by the recovery moments and referring to earlier contracting years.

\section{Conclusions}

The observations regarding the implementation' evolution of the most successful agricultural measure of the NRDP 2007-2013 addressing the support to investments in modernisation of agriculture, the measure 121, highlight several important findings.

A high demand for investments in modernisation is observed, basically for equipment and machinery mainly for field crops, in line with the needs analysis of the programme and its scope and objectives at the level of the analysed measure.

Positive and sustained answer form the side of the administrative management of implementation with an evaluated administrative capacity to screen and evaluate almost 9000 projects and monitor the implementation of almost 3000 contracts.

The combination of high demand and sustained administrative capacity is also reflected by the high level of financial execution of the measure $(122.65 \%)$ considering the entire period of the financial crisis overlapping with a part of the analysed time frame.

An importantly high capacity to support the public investments by private contribution for cofinancing with rates above $50 \%$ of the total value of the projects mobilising over 1 billion EUR from the side of the beneficiaries.

Creation of a good reserve of quality projects from all the selected projects that have not contracted due to the budget allocations for each organised call with an important potential for the current RDP and other future interventions regarding the investments in modernisation of the agriculture. 
The overall learning points contribute to an enlarged knowledge based useful for similar programming experiences and potential implementation orientations in the region with particular emphasis on approaching EU support instruments.

\section{References}

1. Mard (2010). National Rural Development Programme 2007-2013, Fifth Version, http://www.pndr.ro/programul-national-pentrudezvoltare-rurala-2007-2013.html, visited 04.2017, pg. 195-211.
2. Mard (2015). Annual Progress Report on Implementation of the NRDP 2007-2013, http://madr.ro/docs/dezvoltare-rurala/raportanual/Raport-anual-de-progrese-PNDR-2015.pdf, visited 04.2017, pg. 21-30.

3. Papić R. \& Bogdanov N. (2015). Rural development policy - A perspective of local actors in Serbia. Economics of Agriculture, 4, 1079-1093, UDC: 631.017.3:338.43.02(497.11).

4. Stojcheska, M. A., Kotevska, A., Bogdanov, N., \& Nikolić, A. (2016). How do farmers respond to rural development policy challenges? Evidence from Macedonia, Serbia and Bosnia and Herzegovina, Land Use Policy, 59:71-83, https://doi.org/10.1016/j.landusepol.2016.08.019. 